\title{
Development and validation of a multivariable prediction model for mediastinitis poststernotomy
}

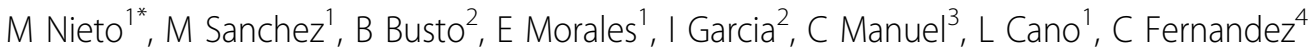 \\ From ESICM LIVES 2015 \\ Berlin, Germany. 3-7 October 2015
}

\section{Introduction}

Mediastinitis is a severe complication of major heart surgery (MHS). Scoring systems constitute a very useful tool for risk assessment and to establish appropriate prevention strategies.

\section{Objectives}

To design a predictive model of mediastinitis for bedside estimation and to develop and validate a risk score for stratification. To compare our model with other indices.

\section{Methods}

Data of 4526 patients admitted after MHS to our Cardiovascular ICU (January 2005,-June 2011) were prospectively collected. After exclusion of 655 patients, 3970 were analyzed to identify risk factors for mediastinitis. A model was generated by logistic regression analysis in a subgroup of 2618 randomly selected patients and validated in a second cohort of 1352 . The discriminatory power was evaluated by area under the receiver operating characteristic curves (AUC-ROC). Calibration was done by the Hosmer-Lemeshow test. The mediastinitisscore ("MED-Score") was created using the points estimate for each variable, with beta coefficients of the final model. For stratification three risk levels were generated.

We assessed the ability of "MED-Score, Euroscore (ES)1, and the Society of Thoracic Surgeons score (STS)2 to predict mediastinitis using ROC curves comparison (MannWhitney). Concordance of risk stratification by scoring systems was evaluated using weighted Kappa index. We used SPSS vs15.0. and STATA 11.0. The outcome "mediastinitis" was defined according to CDC criteria.

${ }^{1}$ Hospital Clinico San Carlos, Intensive Care, Madrid, Spain

Full list of author information is available at the end of the article

\section{Results}

94 (2.4\%) patients developed mediastinitis. Four preoperative (age $>70$, COPD, BMI $>30$ and antiplatelet therapy) and 3 perioperative predictors of mediastinitis (ischemia time, emergency reoperation and prolonged intubation) were identified and included in the logistic model, which accurately predicted outcome (AUC.ROC $0.80)$. Hosmer-Lemeshow test $p=0.46$. The AUC for preoperative Society of Thoracic Surgeons (STS), and combined STS, logEuroScore had a lower discrimination power than MED-Score. This difference was statistically significant. Concordance of risk stratification by the different scoring systems was poor (Kappa< 0.20).

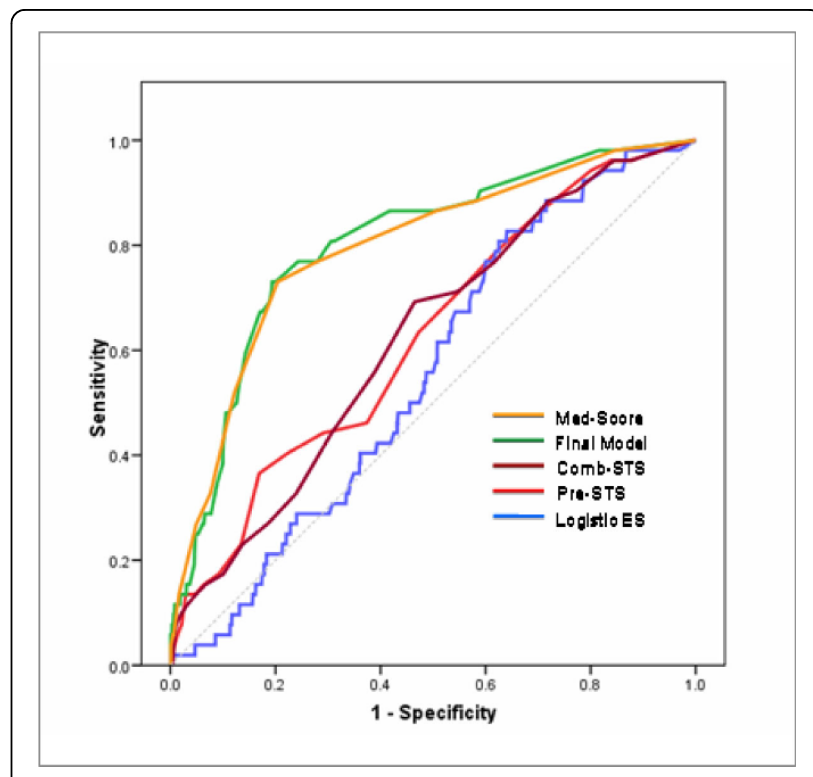

Figure 1 Discrimination models

(c) 2015 Nieto et al.; This is an Open Access article distributed under the terms of the Creative Commons Attribution License (http:// creativecommons.org/licenses/by/4.0), which permits unrestricted use, distribution, and reproduction in any medium, provided the original work is properly cited. 


\section{Conclusions}

The predictive model based on 7 factors showed excellent predictive power. Our score provides a simple tool for stratification of MHS patients. High-risk patients may be targeted for prevention strategies. In our cohort of patient the STS scores and logES are suboptimal predictors of mediastinitis.

\section{Authors' details}

${ }^{1}$ Hospital Clinico San Carlos, Intensive Care, Madrid, Spain. ${ }^{2}$ Hospital Clinico San Carlos, Madrid, Spain. ${ }^{3}$ Hospital Clinico San Carlos, Cardiac Surgery,

Madrid, Spain. ${ }^{4}$ Hospital Clinico San Carlos, Epidemiology Unit, Madrid, Spain.

Published: 1 October 2015

\section{References}

1. Roques, et al: Eur Heart J 2003, 24(9):882-3, May;

2. Fowler, et al: Circulation 2005, 112(suppl):1358-65.

doi:10.1186/2197-425X-3-S1-A955

Cite this article as: Nieto et al:: Development and validation of a multivariable prediction model for mediastinitis poststernotomy. Intensive Care Medicine Experimental 2015 3(Suppl 1):A955.

\section{Submit your manuscript to a SpringerOpen ${ }^{\circ}$ journal and benefit from:}

- Convenient online submission

- Rigorous peer review

- Immediate publication on acceptance

- Open access: articles freely available online

- High visibility within the field

- Retaining the copyright to your article 